\title{
From ameloblast to iconoclast: Remembering Aubrey
}

\author{
J. Sinclair-Cohen ${ }^{1}$
}
IN BRIEF
- Gives a qualitative view of the contribution of Professor Aubrey Sheiham to public health, to dentistry and to dental education.
- Provides a philosophical perspective.
- Puts his work in the context of public health.
- Shows the relevance of his work for those not versed in public health.

\begin{abstract}
The late Professor Aubrey Sheiham shaped dental public health as a discipline. He leaves behind cohorts of confident public health professionals in dentistry worldwide, including many former students, each with their own kaleidoscope of memories of him as teacher, mentor, colleague and friend. A paper that he published in The Lancet in 1977 famously challenged the prevailing paradigm on dental recalls. For such iconoclasm, I remember him as the dentist who dared disturb the universe.
\end{abstract}

It was our first term at dental school, at 'the London' as it was then called. One winter's afternoon, late in 1979, we were finishing off a session on comparative dental anatomy with an assortment of animal skulls. Back then practical work was carried out in a large grey concrete box of a building on Newark Street known as 'Colditz'. Toward the end of the session in slipped a tutor from another department. He wore cords and a brightly coloured jumper.

Surveying the selection of skulls out on the bench he said, 'There's a paper that has been published that describes human skulls from Saxon times. The interesting thing is that the teeth show little evidence, if any, of dental decay. Why do you think this is?'

'Look,' he said with a twinkle in his eye, 'enamel is the toughest material in our bodies. And when there is an airline disaster this is all that remains. This is how victims are identified. Yet this - the toughest stuff in our bodies - is destroyed by sugar in the diet.' I'd been aware that only the teeth remained after an air crash. Likewise that sugar made holes in teeth. Yet I'd never connected the two in this way before.

Until now our studies had been largely descriptive. Along with general anatomy and histology, we had been learning about the development of teeth, amelogenesis - a process more carefully choreographed than synchronised swimming at the Olympics.

'Evidents Consulting, 33 Nachal Tzofar, Modiin 7174980, Israel

Correspondence to: J. Sinclair-Cohen

Email: judith@evidentsconsulting.org

Accepted 10 May 2016

DOI: 10.1038/sj.bdj.2016.442

${ }^{\circledR}$ British Dental Journal 2016; 220: 619-621
We had looked at the structure of enamel, dentine and cementum under the microscope; and hydroxyapatite under the electron microscope.

At the outset of dental school we had assumed that teeth were passive in the face of caries, only to be rescued by clinical intervention; indeed this seemed to be the raison d'être of dentistry. Yet under the microscope we saw that the tooth does, in fact, actively respond to carious attack. Parallel to the carious lesion it lays down secondary dentine, taking calcium from the pulp, the tooth's blood supply. Moreover, on the microscopic level the outer surface of the tooth was known to be in a constant state of de- and re-mineralisation; an equilibrium that we later learned can be favourably influenced by judicious use of fluorides.

This healthy respect for enamel was further insinuated in biochemistry lectures, when we were shown - equations and all - that saliva is actually a highly effective buffer in the face of acidic attack. The system, however, is simply overridden by amounts of sugar in the modern Western diet far in excess of what nature intended; hence the healthy teeth on those Anglo Saxon skulls.

There was something different about this engaging teacher with curly hair and roundrimmed glasses that made me wonder just who he was. Over coffee in the 'Clubs Union' the following morning I asked one of the more senior clinical students. The response left me in no doubt that he was something of a rebel.

Aubrey Sheiham was then a senior lecturer in the department of community dental health, having previously worked as a senior lecturer in periodontics. There was only one other teacher referred to in student conversation exclusively by their first name. And he was dean.

The dental school took pride in stressing patient care in the context of their individual life. Aubrey, however, took things a step further with a population perspective. And in his seminars, epidemiological evidence was set before us as to why dental caries was not inevitable. There were the natives of the island of Tristan da Cunha in the Indian Ocean who barely experienced caries until the arrival of sugar from the mainland in the sixties; likewise populations of children in Europe and Japan during WW2 when sugar was scarce; not forgetting a small study on those born with hereditary fructose intolerance who (couldn't digest, and so) never ate fructose, a component of sucrose. Added to this was evidence from a selection of clinical studies that, with the relationship between sugar and caries now being so firmly established, would no longer be considered ethical today.

The department of community dental health was in Ashfield Street and Aubrey's office was on the first floor. There was the odd ornament from his native South Africa and several plants; but the room was dominated by a large desk with a framed photograph of his wife Helena, and a stacked in-tray that seemed to continue upward to the ceiling. He was very approachable in what was generally a very formal atmosphere. And it wasn't unusual for him to sort out an exquisitely complicated problem that burdened a student.

The reason Aubrey was considered resident revolutionary, I later learned, was due to a paper that he had published a couple of years previously in The Lancet. This paper 
- published in the most prestigious of medical journals - questioned the evidence for dental check-ups every six months. ${ }^{1}$

His arguments were scientific and clear. He drew largely on the classic work of Wilson and Jungner and their ten principles of screening; a key principle being that screening should be appropriate to the life history of the disease. ${ }^{2}$ Aubrey put this in the dental context. He argued that if, for patients over the age of twelve, it took two years for dental caries to progress from the outer surface of enamel to dentine, then there should be no need to recall patients as frequently as every six months. Moreover, he presented evidence that suggested that dental patients who attended more frequently did not end up with better oral health, hinting at the risk of overtreatment.

This recall interval had not been challenged since it had been arbitrarily proposed in the 1850s. The arguments in the Lancet paper were rational. But, as Nobel Prize winner Daniel Kahneman has shown, human behaviour can be far from rational. The dental profession was in uproar. With dental practice entrenched in drill and fill, the benefit of early operative intervention was a fundamental belief. And with a remuneration system based on the amount of treatment carried out, dentists felt that their livelihood was under threat.

Aubrey was a clear communicator and an eloquent speaker. As a true educator he actively engaged debate: What evidence is there that brushing prevents caries? None. It's the fluoride toothpaste that prevents decay not the brushing per se. We would joke that at the mention of the word fluoride the pupils of his eyes would dilate. We once all traipsed up to Westminster by tube to hear him speak in a debate on fluoridation in the House of Lords. The arguments of the anti-fluoridation lobby were dissected one by one. Whatever the comment thrown at him - and issues surrounding safety and children can be quite emotive - he would calmly deal with it with indomitable confidence. In his seminars, epidemiological evidence was laced with entertaining anecdotes like that of the public announcement that the water in Birmingham had been fluoridated; this precipitated a flurry of phone calls from the public that their water/tea/coffee didn't taste the same. It then became apparent that fluoride hadn't yet been added to the water!

At the time the causes of dental caries were safely labelled 'multi-factorial' and tidied up into a Venn diagram embracing tooth, sugar, bacteria and time. ${ }^{3}$ There was a strong belief in germ theory with streptococcus mutans always at the scene of the cariogenic crime. To give an idea of how seriously this model was taken in the early eighties, another leading dental school was trying to develop a vaccine against streptococcus mutans on monkeys. So confident was this avenue of research, that there was even a (short-lived) special edition of the standard immunology textbook for dentists with the relevant chapters added.

Aubrey pointed to social causes of disease and the contribution to be made by social sciences to understanding health. Such was the status of these subjects that they were non-existent in the dental curriculum, and affectionately referred to by the then medical students as 'The Sillies'. Aubrey was keen to stress that the evidence showed that it was those in lower socio-economic groups who were most in need of fluoridated water and benefited most. He seemed to enjoy dispersing fallacies; no, black people didn't have worse gum disease than white people, not when you factor in social class. He also tuned us into cultural sensitivities. Yes, the government fortified margarine with vitamins $\mathrm{A}$ and D but the local Asian women in London's East End who were prone to this deficiency, from lack of exposure to the sun, didn't use margarine; they used ghee.

Aubrey showed that an increase in caries for populations was closely associated with increased consumption of sugars with a dose response curve. ${ }^{4}$ In parallel to sound research he had a very original way of looking at situations. For example, he attributed the muchtouted 'dramatic decline' in dental caries in the eighties to widespread use of toothpastes containing fluoride, rather than to dentistry.

By 1984 he was appointed professor of dental public health at UCL and the department was divided between the two dental schools. He was now appropriately ensconced together with the department of epidemiology in Gower Street.

I came back to study for the MSc in Dental Public Health in 1991 (and distinctly remember recognising one of his jumpers from my undergraduate days!) It was an international course that attracted students from all over. Aubrey had designed it to include the disciplines he felt were relevant with an emphasis on primary healthcare, epidemiology and health promotion. A pervasive awareness of the detrimental effect of the food industry was ever present. How Aubrey delighted one day in seeing someone in the supermarket wearing a badge he felt provided a suitable metaphor. It read: 'Humpty Dumpty was pushed'.

He brought in social scientists with an interest in oral health, rather than dentists who dabbled in the subject. When planning services we were encouraged to think of needs beyond the traditional DMF index, which tots up the number of decayed, missing and filled teeth. Instead, patient perceptions and the impact on their life were considered. In orthodontics, for example: the dentist, the orthodontist, the parent, the child and school friends might each have very different views on the need for treatment.

We were taught through basic enduring principles, and so even though my work in public health has taken me far from dentistry, whatever the context - clinical trials, ethics, access to care, ageing - that training has been transferrable.

In response to the explosion of dental caries in developed countries in the fifties and sixties, dentistry rose to the challenge with dental research which - for the main - focused inwards, with improved diagnostic and clinical techniques, and delivery of care. Thus, improved methods of radiography requiring less radiation were developed; teeth that once might have been extracted were root filled as endodontics developed into a speciality; and children's decayed deciduous teeth were treated, rather than being overlooked in anticipation of the permanent teeth; acceptable approaches to local anaesthesia in children were developed. Meanwhile, dental materials were continuously enhanced by academia and industry for easier handling, biocompatibility, better thermal properties, improved resilience in the mouth's corrosive milieu and, of course, for enhanced aesthetics.

In contrast to the rest of the profession, Aubrey looked outwards to the origins of dental diseases. He looked outwards: to Cochrane, ${ }^{5}$ Illich, ${ }^{6}$ McKeown ${ }^{7}$ and later Geoffrey Rose. ${ }^{8}$ He taught that where someone lived could tell us more about their oral health than by looking in their mouth. This holds true for populations of people - not for individuals. Research in the department looked at the social gradient of oral health, bringing it in line with other research in public health. All manner of influences on people's oral health beyond that tidy Venn diagram were reflected in a plethora of postgraduate theses.

At times the need for evidence could get a bit much. I remember once telling Aubrey that my sister-in-law had triplets. 'There's an interesting study on the needs of higher-order births', he said. 'For example they found that you can't get a three-way buggy in a lift.' At this I got the giggles. 'Don't you think that that's rather obvious?' I asked. He was horrified. 'Well sometimes it is and sometimes it isn't, that's why we have to do research,' he replied.

The best lectures were in philosophy of science. According to philosopher Thomas Kuhn, for each discipline, however much one questions things there is still a basic 
fund of ideas, a paradigm, which is intrinsically resistant to change. ${ }^{9}$ Think Galileo. Think Semmelweis, the nineteenth century Hungarian doctor who showed that mothers who gave birth in the doctors' ward were three times more likely to die from puerperal fever than those in the midwives' ward. A statistic that - years ahead of Pasteur and Lister - he attributed to hand washing. The medical profession, incensed at the suggestion that they should wash their hands criticised him rather than the data. Evidence aside, Semmelweis was put in a mental asylum, where he eventually died.

Aubrey wasn't treated quite as badly as Semmelweis, but it was unpleasant just the same. The fallout reverberated well into the nineties when he once confided that there was still the odd clinician from the Dental Institute who crossed over to the other side of Stepney Way when they saw him approach.

Looking back, he came to dental public health at a pivotal time: When the radical and charismatic Ivan Illich came to London, Aubrey went to hear him speak. He also made tracks to Alma Ata to attend the WHO declaration of Primary Health Care in $1978 .^{10}$ This was around the same time Thomas McKeown published The Role of Medicine showing that death rates from tuberculosis, which was a number one killer in the nineteenth century, dropped before the advent of streptomycin or the BCG vaccination around 1950; actually, the number of deaths started to fall even before Koch identified the tubercle bacillus in the 1880s. ${ }^{7}$ McKeown's groundbreaking work suggested that the reasons for improvements in health in the twentieth century were more complex than previously thought; improvements that were more likely due to better living conditions and nutrition than to attenuated bacteria. This was a tipping point in public health.

Essentially, Aubrey translated developments in public health to the betterment of oral health. And an evidence-based approach secured a true trajectory for dental public health, endorsing it as a serious discipline within dentistry. Long before Cochrane catapulted into clinical medicine, reference seven of that paper in The Lancet back in 1977 was from his seminal work, Effectiveness and Efficiency. ${ }^{5}$ Incidentally, the National Institute of Clinical Excellence endorsed Aubrey's views on dental check-ups in 2004. ${ }^{11}$

According to management guru Stephen Covey, leadership is about where to put the ladder rather than how to climb it. So while the scientific basis for prevention is supported and enriched by extensive research (and great strides have been made at the clinical coalface of community dentistry), what distinguished Aubrey was his leadership. After all, dental caries and periodontal diseases are largely preventable and sound tooth is superior to any dental material.

When Aubrey passed away last November I hadn't seen him in many years. But a few months ago I had BBC Radio 4 playing while busy in the kitchen, when above the whirr of the food processor I discerned what I thought was a familiar voice. The subject - six-monthly dental recalls. I turned off the machine to listen to those eloquent familiar sound bites. After all these years, how it upset me to detect just a frisson of frustration as he spoke on the subject.

Extraordinary Aubrey!

Others reflect on his global reputation in public health and his scholarship. ${ }^{12}$ I look back and remember a splash of colour on a bleak wintry day; an in-tray reaching for the ceiling; Aubrey holding court with treasured evidence.

This is how I remember him.

And yes. It moves.

Acknowledgement

The author wishes to thank Dr Helena Cronin for her discerning comments on the manuscript.

1. Sheiham A. Is there a scientific basis for sixmonthly dental examinations?' Lancet 1977; 2: 442-444.

2. Wilson J M G, Jungner G. Principles and practice of screening for disease. Geneva: World Health Organization, 1968.

3. Mandel I D, Zengo A N. Comparative immunology of the oral cavity. In Mergenhagen S E, Sherp H W (eds) Genetic and chemical aspects in caries resistance. pp. 118-137. Washington: US Department of Health, Education and Welfare, 1973.

4. Sheiham A. Why free sugars consumption should be below $15 \mathrm{~kg}$ per person per year in industrialised countries: the dental evidence. $\mathrm{Br}$ Dent J 1991; 171: 63-65.

5. Cochrane A L. Effectiveness and efficiency: random reflections on health services. London: Nuffield Provincial Hospital Trust, 1972.

6. Illich I. Limits to medicine. Medical nemesis: The expropriation of health. London: Penguin, 1977.

7. McKeown T. The role of medicine. Oxford: Basil Blackwell, 1979.

8. Rose G. The strategy of preventive medicine. Oxford: Oxford University Press, 1992.

9. Kuhn T S. The structure of scientific revolutions. 1st edition. University of Chicago: Chicago Press, 1962.

10. WHO. Declaration of Alma Ata. International conference on primary health care, Alma-Ata, USSR, 6-12 September 1978. Available online at http://www.who.int/publications/almaata_ declaration_en.pdf (accessed March 2016).

11. National Institute for Health and Clinical Excellence. Dental checks: intervals between oral health reviews. NICE guidelines [CG19]. 2004. Available online at https://www.nice.org.uk/ guidance/cg19 (accessed March 2016).

12. Watts G. Aubrey Sheiham. Lancet 2015; 386: 2388. 